\title{
EXISTENCE THEORY FOR FRACTIONAL-ORDER \\ NEUTRAL BOUNDARY VALUE PROBLEMS
}

\author{
Bashir Ahmad, Sotiris K. Ntouyas, Ahmed Alsaedi And Manal \\ ALNAHDI
}

Abstract. A new class of Dirichlet boundary value problems of Caputo-Hadamard type fractional neutral differential equations and inclusions is studied. Expressions for Green's functions are derived to obtain the integral equation equivalent to the associated single-valued problem. Existence and uniqueness results are proved for single-valued and multivalued problems at hand. Examples demonstrating the application of the main results are presented. Finally we extend our discussion to the case of three-point nonlocal boundary conditions.

Mathematics subject classification (2010): 34A08, 34B15, 34A60, 34K05.

Keywords and phrases: Caputo-Hadamard fractional differential equations, inclusions, existence, uniqueness, fixed point.

\section{REFERENCES}

[1] V. Kolmanovskit, A. Myshisis, Introduction to the Theory and Applications of FunctionalDifferential Equations, Mathematics and its Applications, 463, Kluwer Academic Publishers, Dordrecht, 1999.

[2] J. Klafter, S. C. Lim, R. Metzler (eds.), Fractional Dynamics in Physics, World Scientific, Singapore, 2011.

[3] R. L. Magin, Fractional Calculus in Bioengineering, Begell House Publishers Inc., U.S., 2006.

[4] A. A. Kilbas, H. M. Srivastava, J. J. Trujillo, Theory and Applications of Fractional Differential Equations, North-Holland Mathematics Studies, 204, Elsevier Science B. V., Amsterdam, 2006.

[5] M. Benchohra, J. Henderson, S. K. Ntouyas, A. OuAhab, Existence results for fractional order functional differential equations with infinite delay, J. Math. Anal. Appl. 338 (2008), 1340-1350.

[6] R. P. AgARWAL, Y. ZHOU, Y. HE, Existence of fractional neutral functional differential equations, Comput. Math. Appl. 59 (2010), 1095-1100.

[7] Y. Zhou, F. JiAO, J. PECARIC, Abstract Cauchy problem for fractional functional differential equations, Topol. Methods Nonlinear Anal. 42 (2013), 119-136.

[8] B. Ahmad, S. K. NTOUYAs, Initial value problems for functional and neutral functional Hadamard type fractional differential inclusions, Miskolc Math. Notes 17 (2016), 15-27.

[9] H. ERGÖREN, B. AHMAD, Neutral functional fractional differential inclusions with impulses at variable times, Dyn. Contin. Discrete Impuls. Syst. Ser. B Appl. Algorithms 24 (2017), 235-246.

[10] H. BAO, J. CAO, Existence of solutions for fractional stochastic impulsive neutral functional differential equations with infinite delay, Adv. Difference Equ. (2017), 2017:66.

[11] M. A. KRASNOSELSKII, Two remarks on the method of successive approximations, Uspekhi Mat. Nauk 10 (1955), 123-127.

[12] H. Covitz, S. B. NADLER JR., Multivalued contraction mappings in generalized metric spaces, Israel J. Math. 8 (1970), 5-11.

[13] M. Kisielewicz, Differential Inclusions and Optimal Control, Kluwer, Dordrecht, The Netherlands, 1991.

[14] C. Castaing, M. Valadier, Convex Analysis and Measurable Multifunctions, Lecture Notes in Mathematics 580, Springer-Verlag, Berlin-Heidelberg-New York, 1977. 
[15] K. Deimling, Multivalued Differential Equations, Walter De Gruyter, Berlin-New York, 1992.

[16] A. Lasota, Z. Opial, An application of the Kakutani-Ky Fan theorem in the theory of ordinary differential equations, Bull. Acad. Polon. Sci. Ser. Sci. Math. Astronom. Phys. 13 (1965), 781-786.

[17] W. V. Petryshyn, P. M. FitZPATRIC, A degree theory, fixed point theorems, and mapping theorems for multivalued noncompact maps, Trans. Amer. Math. Soc., 194 (1974), 1-25.

[18] A. Petrusel, Fixed points and selections for multivalued operators, Seminar on Fixed Point Theory Cluj-Napoca 2 (2001), 3-22. 